\title{
Study Protocol for Draup: De-implementation Ofroutine Chest Radiographs After Adoption of Ultrasound Guided Insertion and Confirmation of Central Venous Catheter Protocol, A Hybrid Implementation/effectiveness Study
}

\section{Enyo A. Ablordeppey ( $\nabla$ ablordeppeye@wustl.edu )}

Washington University in Saint Louis John M Olin Library https://orcid.org/0000-0003-4351-6720

Byron J. Powell

Washington University in Saint Louis

Virginia R. McKay

Washington University in Saint Louis

Shannon M. Keating

Washington University in Saint Louis

Aimee S. James

Washington University in Saint Louis

Christopher R. Carpenter

Washington University in Saint Louis

Marin H. Kollef

Washington University in Saint Louis

Richard T. Griffey

Washington University in Saint Louis

\section{Study protocol}

Keywords: ultrasonography, critical care, de-implementation, central venous catheter, chest radiography

Posted Date: June 26th, 2020

DOI: https://doi.org/10.21203/rs.3.rs-37859/v1

License: (c) (i) This work is licensed under a Creative Commons Attribution 4.0 International License. Read Full License 


\section{Abstract}

\section{BACKGROUND}

Avoiding low value medical practices is an important focus in current healthcare utilization. Despite advantages of point of care ultrasound (POCUS) over chest x-ray (CXR), including improved workflow and timeliness of results, POCUS-guided central venous catheter (CVC) position confirmation and exclusion of pneumothorax (PCEP) has had slow rate of adoption. This demonstrates a gap that is ripe for the development and application of de-implementation strategies that support substitution of POCUS for CXR after CVC insertion.

\section{METHODS}

De-implementation of routine chest radiographs after adoption of $\underline{u}$ ltrasound guided insertion and confirmation of central venous catheter protocol (DRAUP) will be created to de-implement an unnecessary imaging modality in the critical care environment. Guided by the Consolidated Framework for Implementation Research constructs, we will explore barriers and facilitators of POCUS for CVC PCEP in a single center, large tertiary, academic hospital via focus groups. The focus groups will inform the development and testing of strategies that address identified determinants of implementation and deimplementation.Operational use of the de-implementation strategies will be conceptualized using Morgan's framework for understanding and reducing medical overuse. We will locally implement these strategies and assess them using Proctor's outcomes (adoption, de-adoption, fidelity and penetration) in an observational study to demonstrate proof of concept, gaining valuable insights on our selected implementation and de-implementation strategies. Secondary outcomes will include POCUS-guided CVC PCEP efficacy measured by time and effectiveness measured by sensitivity and specificity of POCUS detection.

\section{DISCUSSION}

With limited data available to inform interventions that use concurrent implementation and de-implementation strategies to substitute CXR for POCUS using DRAUP, we propose that this primary implementation and secondary effectiveness pilot study will provide novel data that would expand the knowledge of replacing low value or unnecessary care in critically ill patients.

Trial Registration: ClinicalTrials.gov Identifier, NCT04324762, Registered on 27 March 2020

\section{Contribution To The Literature}

- This study highlights the use of implementation science in critical care medicine by proposing de-implementation of (unnecessary) low value medical care

- This study will add to the limited data on coupled/grouped implementation and deimplementation strategies in the advancement of an evidence-based innovation

- This study demonstrates a multi-framework analysis for complex behavior change exploration (CFIR, Consolidated Framework for Implementation Research), de-implementation (Morgan's Framework for understanding and reducing overuse) and evaluation (Proctor's conceptual model for implementation research)

\section{Background}

De-implementing unnecessary health interventions is essential for improving population health and reducing unnecessary waste in health care and public health.[1] It is estimated that $30 \%$ of medical interventions are unnecessary, suggesting that there are areas of medical overuse.[2] One example of an unnecessary intervention is the use of chest radiographs (CXR) after central venous catheter (CVC) insertions. The placement of CVCs is a common procedure performed in critically ill 
patients, with five million placed annually[3]. The routine use of CXR for CVC confirmation is an outdated practice that fails to take advantage of the now ubiquitous use of point of care ultrasound (POCUS) for CVC placement to then confirm CVC position. [4-6] CXR is an overused resource because providers already using POCUS for CVC insertion can quickly use it to confirm catheter position confirmation and exclude pneumothorax (PCEP) immediately after the procedure.

Observational data and a randomized controlled trial (RCT) have shown that POCUS can also provide similar yet faster diagnostic information to CXR after CVC insertion, thus demonstrating superior efficiency.[7-10] A POCUS-guided CVC PCEP protocol consists of three ultrasound imaging steps (Fig. 1). Three recent meta-analyses found that POCUS for CVC position confirmation was feasible (98\% adequate visualization), fast (reducing mean CVC confirmation time compared to CXR), and accurate. $[7,9,11]$ In the RCT, POCUS-only CVC PCEP reduced the time from insertion to first use of CVC and reduced overall CXR utilization by 56.7\% ( $\mathrm{P}<$.0001).[9] Additionally, the annual cost to the United States healthcare system for CXRs after CVC placement exceeds $\$ 500$ million.[12] Thus, CXRs represents avoidable costs and resource utilization to the health care system, results in ionizing radiation exposure, and delays in patient care. $[9,10,13-15]$

Despite advantages of POCUS over CXR, including that POCUS is easy to perform, faster, and is non-inferior to CXR, POCUSguided CVC PCEP has had slow rate of clinical adoption. $[9,10,13-16]$ Even among providers with ultrasound experience, self-reported use of POCUS for CVC PCEP and de-adoption of CXR is low (1.5\%), citing various barriers to this practice.[17, 18] This demonstrates an important gap, necessitating advance in this space. De-implementation of routine chest radiographs after adoption of ultrasound guided insertion and confirmation of central venous catheter protocol (DRAUP) is designed to take advantage of an evidenced-based innovation (EBI) and de-implement low value CXR in the critical care environment using strategic interventions. Few barriers and effective strategies to de-implementation have been explored that are generalizable to this context.[1] In this study, we will identify barriers towards deimplementation of low value care (i.e., CXR for post CVC insertion), facilitate the adoption of DRAUP with multifaceted strategies against the identified barriers, allowing them to de-implement post procedure CXR, and evaluate appropriate outcomes.

\section{Methods/design}

Study procedures have been approved by Washington University School of Medicine Institutional Review Board. We have initiated DRAUP in the emergency department (ED) and are beginning to use the multifaceted strategies (January 2020). This study will be performed at a tertiary academic medical center.

\section{Study population, subjects, and recruitment}

In aim 1, we will conduct focus groups of practicing critical care medicine and emergency medicine (EM) physicians to discuss current practices in ultrasound-guided CVC PCEP. These physicians are most familiar with CVC confirmation by current standards and have the best knowledge of heart, lung, and vascular imaging by POCUS. Participants will be recruited from our local health system, selected by purposive sampling, and carefully identified to reflect variations in practice settings (academic and community) to capture a broad range of beliefs towards CVC position confirmation practice.[19] Motivation to participate is based on the voluntary selection of early adopters of POCUS related innovations. [20] Additional focus groups will include physician administrators and nursing leadership as stakeholders because they can foster a positive implementation climate and can ensure organizational readiness for change. Contact will be initiated via email requests for participation.

In aim 2, study participants will be senior (3rd \& 4th year) EM residents and faculty members. This is the group who will be performing DRAUP. This subject group will be chosen given previous data demonstrating that this group established adequate retention of ultrasound knowledge and skill for ultrasound guided CVC confirmation.[21] The senior EM residents and faculty will be recruited via email request for participation in protocol education and training. They will undergo a 30minute didactic training and will demonstrate adequate ultrasound image acquisition and interpretation, verified by instructor (EAA), who is clinically trained and certified in EM, critical care medicine, and ultrasonography.

Page $3 / 16$ 


\section{Stakeholders engagement}

Relevant stakeholders to implementing the evidence-based innovation of POCUS guided CVC PCEP include medical providers who will perform the DRAUP protocol, the EM administrators who must buy into the DRAUP protocol, and nurses who are taking care of the patient. Intensive Care Unit (ICU) physicians and ICU nursing leadership also serve as gatekeepers. Stakeholders and gatekeepers will be involved by participating in a qualitative exploratory analysis as well as empowering the institutional climate of change.

\section{Procedures, Instruments, and Design}

\section{Aim 1: Exploration by Qualitative methods}

During the exploration phase, the Consolidated Framework in Implementation Research [22] will be used to understand the contextual environment in which barriers and facilitators to adoption exist. Focus groups will be chosen to allow inductive facilitators and barriers to emerge in a group setting. An interview guide informed by the CFIR will be used for each focus group and is included in the supplementary file 1. To address questions focused on barriers to implementing POCUS guided CVC confirmation and substitution of POCUS instead of CXR, we will target the inner and outer setting as well as individual constructs. For example, we will ask about EBI knowledge, hospital policy, and capability for change. CFIR is our chosen framework as it best fits our study goals about understanding the organizational and personal contexts that are preventing the de-implementation of CXR and the implementation of POCUS. A moderator who has experience conducting focus groups will lead all the focus groups for consistency. Field notes with written observations will be created during each focus group. We estimate approximately 5-8 focus groups made up of 5-7 physicians. This sample size is adaptative to the attainment of theme saturation, meaning focus groups will be continued beyond 8 sessions until thematic saturation of barriers has been achieved.[23-25] This qualitative data will inform implementation and de-implementation approaches that are more likely to be accepted, adopted, and maintained by our target population in the ED.[26]

\section{Qualitative Analysis}

Focus groups and field notes will be recorded and transcribed verbatim by a professional transcription company and will be checked for accuracy by $10 \%$ manual proof reading of the transcript to digital recording a research team member (SMK). Two research team members (EAA, SMK), experienced in qualitative research will independently code the de-identified transcripts for content (NVivo 12, QSR Industries, Doncaster, AU). A comprehensive coding scheme will be developed based on a close reading of the text. A coding dictionary will be developed that includes specific definitions of each code and criteria for good examples of code applications.[27] We will use the deductive codes created using CFIR constructs and inductive codes that are discovered in the coding of transcripts to generate a codebook. We will then review transcripts for preliminary identification of inductive codes and then finalize the codebook. The two coders (EAA, SMK), will then independently recode all transcripts using the newly created codebook. Level of agreement between the two coders based on the codebook will be calculated by Cohen's Kappa to ensure accuracy of the codebook. Coding discrepancies will be reviewed with a qualitative methods expert (ASJ) and will be discussed until Cohen's Kappa is greater than 0.9. The process will continue iteratively until the codebook is complete. This codebook will then be used to code all subsequent focus group transcripts. The qualitative data from the focus groups will allow consensus identification and descriptions of barriers and facilitators towards the EBI.

\section{Aim 2: Execution by implementing a protocol (DRAUP) and studying the multicomponent implementation strategies}

During the implementation phase, the DRAUP protocol will include substitution of routine post-procedure CXR in a local ED after appropriate performance and documentation of POCUS guided CVC CPEP. Execution of DRAUP will be guided by a framework that highlights the specific process of de-implementation. We will design a multifaceted strategy bundle guided 
by Morgan's framework for medical overuse and will tailor the strategies to any additional determinants identified in Aim 1. [28] This framework also allows prioritization of specific interventions toward understanding medical overuse and deimplementation (Fig. 2).

\section{Multifaceted Strategies}

We will identify a multifaceted strategy bundle (that targets both implementation and deimplementation) that we believe to be feasible, adaptable, generalizable, and informed by our focus group barriers and Morgan's framework for medical overuse.[28] (Table 1) These strategies will address the possible domains/drivers of influence for understanding medical overuse: Audit \& Feedback, Algorithm development, Planned Adaptation, Organizational Support, Decision Support, Education \& Training. Details of our strategy bundle are described in Table 2. Our strategies incorporate Morgan's framework and target the clinician, clinic environment, culture of healthcare, and practice environment.[28] At the clinician level, strategies include 1) Education and training (academic detailing) with interactive didactics, skill building workshops, 2) clinical decision support, and 3) audit and feedback which we believe to be the most effective strategies for replacing an intervention with a new evidence-based intervention.[1, 29, 30] Education and Training will occur modeling a training protocol used in a recent research demonstrating that POCUS non-experts could achieve adequate knowledge, performance, and interpretation of POCUS guided CVC PCEP.[21] EM ultrasound expert faculty group made up of seven EM attending faculty will provide real time, in-person decision support (education, supervision) for the use of DRAUP. DRAUP utilization will include weekly electronic audit and feedback process in the ED (already part of the ED ultrasound imaging workflow) and every other month summary and assessment to see if there is cumulative change in practice.[31] This frequency of audit and feedback will allow us to perform sensitivity analyses that will be used to identify the optimal timeframe to perform audit and feedback for future larger scale projects.[32] 
Table 1

Implementation and De-implementation strategies informed by Morgan's Practical framework for conceptualizing interventions to reduce medical overuse.

\begin{tabular}{|c|c|c|c|c|c|}
\hline $\begin{array}{l}\text { Morgan's } \\
\text { possible } \\
\text { drivers/domains }\end{array}$ & $\begin{array}{l}\text { Feasible } \\
\text { approaches to } \\
\text { improvement }\end{array}$ & $\begin{array}{l}\text { Barriers to } \\
\text { deimplementation }\end{array}$ & $\begin{array}{l}\text { Intervention } \\
\text { (strategies) }\end{array}$ & $\begin{array}{l}\text { Strategy } \\
\text { description }\end{array}$ & $\begin{array}{l}\text { Level of } \\
\text { intervention } \\
\text { Influence }\end{array}$ \\
\hline $\begin{array}{l}\text { Clinician } \\
\text { factors: belief } \\
\text { that more is } \\
\text { better, poor } \\
\text { knowledge of } \\
\text { evidence, past } \\
\text { experience, } \\
\text { cognitive } \\
\text { dissonance, fear } \\
\text { of litigation }\end{array}$ & $\begin{array}{l}\text { Clinician: } \\
\text { education } \\
\text { about evidence; } \\
\text { education } \\
\text { about harms of } \\
\text { testing in these } \\
\text { patients }\end{array}$ & $\begin{array}{l}\text { Provider lack of } \\
\text { knowledge/practice }\end{array}$ & $\begin{array}{l}\text { Education and } \\
\text { Training }\end{array}$ & $\begin{array}{l}\text { Knowledge } \\
\text { about the } \\
\text { innovation, } \\
\text { skills to use the } \\
\text { innovation, } \\
\text { optimism that } \\
\text { the innovation } \\
\text { will be effective, } \\
\text { and improved } \\
\text { ability to access } \\
\text { details about } \\
\text { how to use the } \\
\text { innovation } \\
\text { without } \\
\text { prompts. }\end{array}$ & Individual \\
\hline $\begin{array}{l}\text { Patient-clinician } \\
\text { interaction: } \\
\text { hypothetical, } \\
\text { poor } \\
\text { communication } \\
\text { secondary to } \\
\text { patient } \\
\text { condition }\end{array}$ & $\begin{array}{l}\text { Physician- } \\
\text { directed tool for } \\
\text { communication } \\
\text { about the issue }\end{array}$ & $\begin{array}{l}\text { Provider lack of } \\
\text { comfort }\end{array}$ & $\begin{array}{l}\text { Decision Support } \\
\text { from DRAUP team }\end{array}$ & $\begin{array}{l}\text { Training and } \\
\text { Supervision: } \\
\text { Reflect on the } \\
\text { implementation } \\
\text { effort, share } \\
\text { lessons learned, } \\
\text { support } \\
\text { learning, and } \\
\text { propose } \\
\text { changes to be } \\
\text { implemented in } \\
\text { small cycles of } \\
\text { change. }\end{array}$ & $\begin{array}{l}\text { Individual and } \\
\text { Social } \\
\text { Network }\end{array}$ \\
\hline $\begin{array}{l}\text { Clinician } \\
\text { factors: belief } \\
\text { that more is } \\
\text { better, poor } \\
\text { knowledge of } \\
\text { evidence, past } \\
\text { experience, } \\
\text { cognitive } \\
\text { dissonance, fear } \\
\text { of litigation }\end{array}$ & $\begin{array}{l}\text { Clinician: } \\
\text { education } \\
\text { about evidence; } \\
\text { education } \\
\text { about harms of } \\
\text { testing in these } \\
\text { patients }\end{array}$ & Inertia & $\begin{array}{l}\text { Audit and } \\
\text { Feedback }\end{array}$ & $\begin{array}{l}\text { Audit feedback: } \\
\text { Provides } \\
\text { clinical } \\
\text { supervision via } \\
\text { digital } \\
\text { assessment, } \\
\text { review case } \\
\text { implementation, } \\
\text { make } \\
\text { suggestions, } \\
\text { and provide } \\
\text { encouragement. }\end{array}$ & $\begin{array}{l}\text { Individual and } \\
\text { Organizational }\end{array}$ \\
\hline
\end{tabular}

DRAUP, de-implementation of routine chest radiographs after adoption of ultrasound guided insertion and confirmation of central venous catheter protocol; ED, emergency department; EBI, evidence based innovation; EMR, electronic medical record 


\begin{tabular}{|c|c|c|c|c|c|}
\hline $\begin{array}{l}\text { Morgan's } \\
\text { possible } \\
\text { drivers/domains }\end{array}$ & $\begin{array}{l}\text { Feasible } \\
\text { approaches to } \\
\text { improvement }\end{array}$ & $\begin{array}{l}\text { Barriers to } \\
\text { deimplementation }\end{array}$ & $\begin{array}{l}\text { Intervention } \\
\text { (strategies) }\end{array}$ & $\begin{array}{l}\text { Strategy } \\
\text { description }\end{array}$ & $\begin{array}{l}\text { Level of } \\
\text { intervention } \\
\text { Influence }\end{array}$ \\
\hline $\begin{array}{l}\text { Culture of health } \\
\text { care: } \\
\text { expectation of } \\
\text { all clinicians } \\
\text { (including } \\
\text { attendings, } \\
\text { consultants, } \\
\text { nursing), } \\
\text { revenue } \\
\text { generating } \\
\text { structure, } \\
\text { organizational } \\
\text { competitiveness, } \\
\text { liability fears }\end{array}$ & $\begin{array}{l}\text { Culture: broad } \\
\text { campaign } \\
\text { across the ED }\end{array}$ & Hospital policy & $\begin{array}{l}\text { Organizational } \\
\text { Support } \\
\text { (policy/procedures) }\end{array}$ & $\begin{array}{l}\text { Organizational } \\
\text { attributes such } \\
\text { as less } \\
\text { bureaucratic } \\
\text { organizational } \\
\text { structure, the } \\
\text { presence of } \\
\text { formalized } \\
\text { practice } \\
\text { policies, } \\
\text { positive } \\
\text { organizational } \\
\text { culture and } \\
\text { climate are } \\
\text { associated with } \\
\text { more favorable } \\
\text { service provider } \\
\text { attitudes } \\
\text { toward } \\
\text { adopting the } \\
\text { EBI }\end{array}$ & Organizational \\
\hline $\begin{array}{l}\text { Practice } \\
\text { environment: } \\
\text { ease of protocol }\end{array}$ & $\begin{array}{l}\text { Practice } \\
\text { environment: } \\
\text { EMR support }\end{array}$ & $\begin{array}{l}\text { Provider lack of } \\
\text { confidence }\end{array}$ & $\begin{array}{l}\text { Algorithm } \\
\text { development based } \\
\text { on EBI }\end{array}$ & $\begin{array}{l}\text { Fidelity refers to } \\
\text { assessment of } \\
\text { adherence and } \\
\text { competence }\end{array}$ & Individual \\
\hline $\begin{array}{l}\text { Patient factors: } \\
\text { expectation of } \\
\text { frequent testing }\end{array}$ & $\begin{array}{l}\text { Patient: provide } \\
\text { information } \\
\text { about options } \\
\text { for treatment }\end{array}$ & Inertia & $\begin{array}{l}\text { Planned } \\
\text { Adaptation }\end{array}$ & $\begin{array}{l}\text { data-informed } \\
\text { changes } \\
\text { (reordering } \\
\text { components, } \\
\text { forestalling or } \\
\text { delaying certain } \\
\text { components, } \\
\text { de-emphasis } \\
\text { and emphasis, } \\
\text { adding } \\
\text { materials or } \\
\text { interventions, } \\
\text { language } \\
\text { and/or cultural } \\
\text { adaptations) } \\
\text { approach to } \\
\text { maintain } \\
\text { intervention } \\
\text { fidelity during } \\
\text { the } \\
\text { implementation } \\
\text { of EBI }\end{array}$ & $\begin{array}{l}\text { Individual and } \\
\text { Organizational }\end{array}$ \\
\hline $\begin{array}{l}\text { DRAUP, de-implen } \\
\text { of central venous } \\
\text { record }\end{array}$ & $\begin{array}{l}\text { ation of routi } \\
\text { eter protocol }\end{array}$ & $\begin{array}{l}\text { est radiographs } \\
\text { emergency depar }\end{array}$ & $\begin{array}{l}\text { loption of ultraso } \\
\text { EBI, evidence bas }\end{array}$ & $\begin{array}{l}\text { yuided insertior } \\
\text { novation; EMR }\end{array}$ & $\begin{array}{l}\text { d confirmation } \\
\text { ctronic medical }\end{array}$ \\
\hline
\end{tabular}


Table 2

Description of specific applications of the multifaceted strategies to promote adoption of DRAUP

\begin{tabular}{|c|c|}
\hline Strategy & Details \\
\hline \multirow[t]{3}{*}{ Audit \& Feedback } & $\begin{array}{l}\text { - Weekly review of ultrasound images by ultrasound faculty (to be standardize in the quality } \\
\text { assurance process) }\end{array}$ \\
\hline & $\begin{array}{l}\text { - Weekly feedback to providers about ultrasound image quality and adherence to the } \\
\text { protocol }\end{array}$ \\
\hline & $\begin{array}{l}\text { - Data report and feedback from electronic medical record is generated and analyzed every } \\
2 \text { months }\end{array}$ \\
\hline \multirow[t]{2}{*}{ Algorithm development } & - Algorithm creation and dissemination \\
\hline & $\begin{array}{l}\text { - Targeted dissemination to pertinent stakeholders such as ED faculty members, ICU faculty } \\
\text { members, ED and ICU administrators, and ED and ICU nursing leadership. }\end{array}$ \\
\hline Planned Adaptation & $\begin{array}{l}\text { - Quarterly reassessment of protocol/strategies to consider adaptations to avoid the new } \\
\text { intervention drifting toward or resembling the old, inappropriate intervention thus requiring } \\
\text { more intense strategies to redirect toward DRAUP }\end{array}$ \\
\hline \multirow{2}{*}{$\begin{array}{l}\text { Organizational Support } \\
\text { (stakeholder } \\
\text { engagement, leadership } \\
\text { buy-in }\end{array}$} & $\begin{array}{l}\text { - Change of official hospital policy to allow ultrasound as an alternative mode of CVC } \\
\text { confirmation. }\end{array}$ \\
\hline & - Active dissemination of policy update supporting DRAUP \\
\hline \multirow[t]{2}{*}{$\begin{array}{l}\text { In-person clinical } \\
\text { Decision Support }\end{array}$} & $\begin{array}{l}\text { - EM ultrasound faculty (DRAUP team members) provide in person decision support to } \\
\text { clinical teams in person }\end{array}$ \\
\hline & $\begin{array}{l}\text { - Creation of DRAUP application site with embedded algorithm, protocol videos, frequently } \\
\text { asked questions, DRAUP team contact }\end{array}$ \\
\hline \multirow[t]{2}{*}{$\begin{array}{l}\text { Education \& Training } \\
\text { (Academic Detailing) }\end{array}$} & $\begin{array}{l}\text { - individual EM senior resident training, grouped EM faculty training with education } \\
\text { refreshment }\end{array}$ \\
\hline & - creation of DRAUP dissemination tools (posters, cards, t-shirts, pens, masks, etc.) \\
\hline
\end{tabular}

To address the culture of change, we will focus on strategies that effect clinic/organizational level such as 4) leadership support/endorsement of removal of the old treatment as the only alternative. For strategies at the practice environment level, 5) an algorithm demonstrating a specific POCUS-guided CVC PCEP was created to meet the needs of the area it would be implemented. After adequate planning and organizational support of the protocol (compliant with hospital process and procedures), we will disseminate the DRAUP algorithm to ED stakeholders including department administration, nursing leadership, and ICU leadership (Fig. 3). The algorithm's organizational support will eliminate institutional requirements for CXR before clinical use of the CVC. To ensure successful implementation and deimplementation strategy development, we will review the implementation strategies quarterly, revise the intervention based on poor interest or fidelity, and 6) develop an adapted implementation plan.[33] Any implementation strategy modifications made to fit clinician or clinic characteristics that occur during the implementation period will be reported as a planned adaptation.[34]

\section{Measures}

The design and reporting of this study adhere to the Standards for Reporting Implementation Science and can be found in supplemental file 2.[35] Operationalization of the constructs measured using Proctor's conceptual model for implementation research are demonstrated in Fig. 4.[36] Of the implementation outcomes described in the literature[37], four proximal outcomes as well as two distal outcomes will be measured in Aim 3. 


\section{Aim 3: Evaluation using Implementation and De-implementation Outcomes}

During the evaluation phase, implementation and de-implementation outcomes from Proctor's conceptual model for implementation research will be used to evaluate the success of the strategies described in Aim 2.[37] We will focus on adoption, de-adoption, fidelity, and penetration as the most optimal outcomes of deimplementation and consider the unintended, negative consequences that may arise from achieving these markers of success. Unintended negative consequences to consider include premature use of the DRAUP protocol outside of the ED environment without adequate training (short-term) or decreased confidence interpreting a CXR for CVC PCEP (long-term). Successful de-implementation outcomes will be defined as outcomes that persist after 1 year of strategy integration. This timeframe was chosen given the characteristics of DRAUP (strength of evidence, magnitude of the problem, and characteristics of the intervention).[38] The ED selected for this proposal has an average of 100,000 patient visits per year with an average of five supra-diaphragmatic CVC insertions per week or 260 supra-diaphragmatic CVCs placed per year. With the selected strategies, we define an increased adoption of DRAUP (accompanied by a de-adoption of CXRs) of at least $50 \%$ at one year as a marker of successful implementation. We hypothesize that there will be interval increases in fidelity and overall penetration of the DRAUP protocol within the ED over the 1-year timespan.

\section{Adoption and De-adoption}

Adoption is defined as the intention, initial decision, or action to try or employ an innovation or evidence-based practice.[37] Although in this context, we will refer to the providers perspective using focus groups to evaluate adoption and de-adoption of the EBI. De-adoption is the discontinuation of a clinical practice after it was previously adopted.[39] After one year, we will measure the uptake of DRAUP by conducting a post-implementation survey assessment of attitudes and perception of providers who participated during the implementation phase. We will use these qualitative methods to expand and more deeply understand quantitative findings of the providers decision to employ the $E B I$, as it is influenced by core elements of appropriateness and feasibility.[40,41] A physicians risk tolerance profile may impact their adoption of a new innovation like DRAUP[42]. We will evaluate participating physicians risk profiles using three validated survey instruments (malpractice fear scale (MFS)[43], risk-taking scale (RTS) [44], and stress from uncertainty scale (SUS)[42]). Assessing the physician's risk profile will extend the understanding in this area by testing the risk association and their intent to adopt DRAUP.

\section{Fidelity}

Fidelity, the degree to which an intervention was implemented as it was prescribed, will be measured to assess the internal validity of the clinical outcomes.[37] In this context, fidelity will be assessed by comparing the original EBI and the disseminated/implemented intervention in terms of adherence to the program protocol.[37] Fidelity will be assessed by measuring adherence to the DRAUP protocol (assessed weekly by audit \& feedback) and the adequacy of the stored POCUS images in the EMR (evaluated by the ultrasound expert faculty).

\section{Penetration}

Penetration is the integration of a practice within a service setting and its subsystems specifically, the number of eligible persons who use a service, divided by the total number of persons eligible for the service.[45] Penetration also can be calculated in terms of the number of providers who deliver a given service or treatment, divided by the total number of providers trained in or expected to deliver the service. The electronic medical record (EMR) will measure these outcomes by calculating the number of actual CVC insertions where DRAUP was used divided by the number of possible CVC insertions where DRAUP could have been used. Likewise, de-adoption will be the number of unnecessary CXRs obtained after DRAUP divided by the number of possible cases where CXR was not indicated. After one year, a $50 \%$ reduction in post CVC insertion CXR will be a marker of successful internal penetrance of substitution of routine CXR for POCUS after DRAUP. Penetration outside the ED will be assessed by measuring the proportion of cases where the receiving clinician does not immediately obtain a CXR after the patient arrives to the ICU. 


\section{Distal outcomes}

In addition to the proximal implementation outcomes, distal outcomes such as service outcomes will be evaluated. Efficiency and effectiveness are service outcomes that are important to long-term sustainability of DRAUP and can be measured using data from EMR. [37] Clinical efficiency has always been a benefit of POCUS.[7] Efficiency in this context is measured by the time needed to perform the POCUS guided CVC position confirmation and exclusion of PTX compared to ordering and performing a CXR. Clinical effectiveness is measured by the diagnostic accuracy of POCUS-guided CVC PCEP compared to in-hospital CXRs (which will be obtained at some point during the patient hospital stay). Descriptive analysis with sensitivity and specificity will be calculated for POCUS guided CVC PCEP using CXR as the reference standard. We will construct a $2 \times 2$ table where "disease-present" will be defined as the detection of catheter malposition or the presence of immediate post-procedural pneumothorax on CXR.

\section{Discussion}

\section{Innovation}

This study contains several important innovations. First, the use of POCUS as a substitute for CXR for CVC confirmation is a relatively new implementation phenomenon although the evidence has been present for over a decade. Although data support the use of POCUS as the first approach for CVC PCEP, current practice patterns demonstrate that its use is nonexistent.[17, 18] Radiography using CXR has been the standard method for confirming CVC placement for over 50 years. DRAUP would be a substantial change in the standard of care thus creating a critical translational gap for innovation implementation. With limited data currently available to inform interventions, we believe that our results will fill a knowledge gap.

Second, a combined approach toward implementation and de-implementation strategies is innovative. Many innovations in health care require a simultaneous adoption of one practice and de-adoption of another previously valued practice to impact the patient.[46] Implementation strategies that support POCUS-guided CVC PCEP do not guarantee deimplementation of the post-procedure CXR at the provider or organizational level given the pervasive asymmetry in human psychology that makes it harder to give up modes of care than to adopt new and more promising modes.[47, 48] The activities required to de-implement a practice, through substitution, might not be the simple inverse of those needed for implementation and diffusion.[48] This study seeks to evaluate coupled, multicomponent strategies with some components targeting de-implementation goals and others targeting implementation objectives. The selected frameworks, deimplementation strategies, and outcomes are relatively new in this context. The strategies that affect de-implementation may overlap with those that affect implementation.[39]

\section{Impact}

Current CVC confirmation by CXR is an outdated and overused resource. Clinicians already using POCUS for CVC insertion can quickly use DRAUP immediately after the procedure with no further confirmatory steps or resources needed. DRAUP would be best suited for academic medical environments where ultrasound equipment and ultrasound knowledge is standardized demonstrating adequate social validity and acceptance of POCUS amongst early adopters[49]. This study has the potential to impact public health by increasing our understanding of simultaneous implementation and deimplementation of physician behavior based on their risk profiles. Findings from this study will have the potential to inform future policy mandates around implementation and substitution. Findings will also add to the implementation science literature by providing information on the impact of policy on implementation of evidence-based innovations and the potential moderating effect of organization- and leader-level variables on implementation. The study also has the potential to improve the quality of care to patients and health care systems by improvements in resource utilization and 
diagnostic efficiency. Exploring the role of the selected implementation and deimplementation strategies in behavioral change of this $\mathrm{EBI}$ is overdue.

\section{Limitations}

This is an observational study at a single center location and will not describe any causal relationships between proposed implementation strategy and measured outcomes. Our implementation and deimplementation strategies will be cumulative; thus, this study is not designed to identify which strategy(ies) are driving the implementation outcome.

\section{Abbreviations}

central venous catheters (CVCs)

point of care ultrasound (POCUS - used interchangeably with "ultrasound")

chest radiograph (CXR)

CVC position confirmation and pneumothorax exclusion (PCEP)

De-implementation of routine chest radiographs after adoption of ultrasound guided insertion and confirmation of central venous catheter protocol (DRAUP)

randomized controlled trials (RCT)

Consolidated framework in research (CFIR)

Emergency Department (ED)

Emergency Medicine (EM)

Intensive Care Unit (ICU)

Evidence based innovation (EBI)

electronic medical record (EMR)

malpractice fear scale (MFS), risk-taking scale (RTS), and stress from uncertainty scale (SUS)

Declarations

\section{Ethics approval and consent to participate}

Study procedures have been approved by the Washington University Institutional Review Board (\#202004042)

\section{Consent for publication}

$\mathrm{n} / \mathrm{a}$

\section{Availability of data and materials}

The datasets used and/or analyzed during the current study are available from the corresponding author on reasonable request. 


\section{Funding}

EAA is funded by the Washington University School of Medicine K12 Mentored Training in Implementation Science grant, Grant Number: K12HL137942. BJP is supported by the National Institute of Mental Health K01MH113806; VRM is supported by the Institute of Clinical and Translational Sciences grant UL1TR002345 from the National Center for Advancing Translational Sciences of the National Institutes of Health. ASJ is supported by the Siteman Cancer Center and the Barnes Jewish Foundation. CRC is supported by grants from the John A. Hartford Foundation and West Health Institute. RTG is supported by grant 1 R18 HS025052-01 from the Agency for Healthcare Research and Quality, grant P30DK092950 from the NIH / National Institute of Diabetes and Digestive and Kidney Disorders, Washington University Center for Diabetes Translation Research.

\section{Authors' contributions}

EAA is the PI on the study and led the protocol development. BJP, VRM, ASJ, CRC, RTG have been integral to the development of the study and comprise my mentorship board. BJP, VRM was involved with the study design.

SMK is the research coordinator for the study. All authors read and approved the final manuscript.

\section{Author details}

${ }^{1}$ Department of Anesthesiology, Washington University School of Medicine, St. Louis, MO, USA. ${ }^{2}$ Department of Emergency Medicine, Washington University School of Medicine, St. Louis, MO,USA. ${ }^{3}$ Brown School, Washington University in St. Louis, St. Louis, MO, USA. ${ }^{4}$ Department of Surgery, Washington University School of Medicine, St. Louis, MO, USA. ${ }^{3}$ Department of Internal Medicine, Washington University School of Medicine, St. Louis, MO

\section{References}

1. Norton WE, Chambers DA. Unpacking the complexities of de-implementing inappropriate health interventions. Implement Sci. 2020;15(1):2.

2. Morgan DJ, Brownlee S, Leppin AL, Kressin N, Dhruva SS, Levin L, et al. Setting a research agenda for medical overuse. Bmj. 2015;351:h4534.

3. McGee DC, Gould MK. Preventing complications of central venous catheterization. New England journal of medicine. 2003;348(12):1123-33.

4. Franco-Sadud R, Schnobrich D, Mathews BK, Candotti C, Abdel-Ghani S, Perez MG, et al. Recommendations on the use of ultrasound guidance for central and peripheral vascular access in adults: a position statement of the Society of Hospital Medicine. J Hosp Med. 2019;14:E1-22.

5. Heffner AC, Androes MP, Wolfson AB. Overview of central venous access. Up To Date. 2017.

6. Schmidt G, Blaivas M, Conrad S, Corradi F, Koenig S, Lamperti M, et al. Ultrasound-guided vascular access in critical illness. Intensive care medicine. 2019;45(4):434-46.

7. Ablordeppey EA, Drewry AM, Beyer AB, Theodoro DL, Fowler SA, Fuller BM, et al. Diagnostic Accuracy of Central Venous Catheter Confirmation by Bedside Ultrasound Versus Chest Radiography in Critically III Patients: A Systematic Review and Meta-Analysis. Crit Care Med. 2017;45(4):715-24.

Page $12 / 16$ 
8. Raman D, Sharma M, Moghekar A, Wang X, Hatipoglu U. Utilization of Thoracic Ultrasound for Confirmation of Central Venous Catheter Placement and Exclusion of Pneumothorax: A Novel Technique in Real-Time Application. J Intensive Care Med. 2017:885066617705839.

9. Bou Chebl R, Kiblawi S, El Khuri C, El Hajj N, Bachir R, Aoun R, et al. Use of Contrast-Enhanced Ultrasound for Confirmation of Central Venous Catheter Placement: Systematic Review and Meta-analysis. Journal of Ultrasound in Medicine.

10. Amir R, Knio ZO, Mahmood F, Oren-Grinberg A, Leibowitz A, Bose R, et al. Ultrasound as a Screening Tool for Central Venous Catheter Positioning and Exclusion of Pneumothorax. Crit Care Med. 2017;45(7):1192-8.

11. Smit JM, Raadsen R, Blans MJ, Petjak M, Van de Ven PM, Tuinman PR. Bedside ultrasound to detect central venous catheter misplacement and associated iatrogenic complications: a systematic review and meta-analysis. Crit Care. 2018;22(1):65.

12. Pikwer A, Bååth $L$, Perstoft I, Davidson B, Åkeson J. Routine chest X-ray is not required after a low-risk central venous cannulation. Acta Anaesthesiol Scand. 2009;53(9):1145-52.

13. Wilson SP, Assaf S, Lahham S, Subeh M, Chiem A, Anderson C, et al. Simplified point-of-care ultrasound protocol to confirm central venous catheter placement: A prospective study. World J Emerg Med. 2017;8(1):25-8.

14. Küchle C, Suttmann Y, Wen M. Placement of Central Venous Dialysis Catheters without X-Ray: Safety and Feasibility. Journal of Nephrology \& Renal Diseases. 2017;2017.

15. Blans MJ, Endeman $\mathrm{H}$, Bosch $\mathrm{FH}$. The use of ultrasound during and after central venous catheter insertion versus conventional chest X-ray after insertion of a central venous catheter. Neth J Med. 2016;74(8):353-7.

16. Soni NJ, Reyes LF, Keyt H, Arango A, Gelfond JA, Peters JI, et al. Use of ultrasound guidance for central venous catheterization: a national survey of intensivists and hospitalists. J Crit Care. 2016;36:277-83.

17. Ablordeppey EA, Drewry AM, Theodoro DL, Tian L, Fuller BM, Griffey RT. Current Practices in Central Venous Catheter Position Confirmation by Point of Care Ultrasound: A Survey of Early Adopters. Shock. 2018.

18. Tran QK, Foster M, Bowler J, Lancaster M, Tchai J, Andersen K, et al. Emergency and critical care providers' perception about the use of bedside ultrasound for confirmation of above-diaphragm central venous catheter placement. Heliyon. 2020;6(1):e03113.

19. Palinkas LA, Horwitz SM, Green CA, Wisdom JP, Duan N, Hoagwood K. Purposeful sampling for qualitative data collection and analysis in mixed method implementation research. Administration Policy in Mental Health Mental Health Services Research. 2015;42(5):533-44.

20. Rogers EM, Murcott S. Attributes of innovations and their rate of adoption. Diffusion of innovations. 1995:204-51.

21. Ablordeppey EADA, Anderson A, Casali D, Wallace L, Kane D, Fuller BM, Theodoro DL,. Bedside Ultrasound Guided Central Venous Catheter Confirmation in Critically ill Patients. Academic Emergency Medicine. 2019;Volume 26, Issue S. First published: 22 April 2019.

22. CFIRguide.org. The Consolidated Framework for Implementation Research 2019 [.

23. Guest G, Bunce A, Johnson L. How many interviews are enough? An experiment with data saturation and variability. Field methods. 2006;18(1):59-82.

24. Marshall B, Cardon P, Poddar A, Fontenot R. Does sample size matter in qualitative research?: A review of qualitative interviews in IS research. Journal of computer information systems. 2013;54(1):11-22.

25. Sandelowski M. Sample size in qualitative research. Res Nurs Health. 1995;18(2):179-83.

26. Campbell MK, Meier A, Carr C, Enga Z, James AS, Reedy J, et al. Health behavior changes after colon cancer: a comparison of findings from face-to-face and on-line focus groups. Fam Community Health. 2001;24(3):88-103.

27. Daley CM, Kraemer-Diaz A, James AS, Monteau D, Joseph S, Pacheco J, et al. Breast cancer screening beliefs and behaviors among American Indian women in Kansas and Missouri: A qualitative inquiry. J Cancer Educ.

2012;27(1):32-40.

Page $13 / 16$ 
28. Morgan DJ, Leppin A, Smith CD, Korenstein D. A practical framework for understanding and reducing medical overuse: conceptualizing overuse through the patient-clinician interaction. J Hosp Med. 2017;12(5):346.

29. Norton WE, Chambers DA. Unpacking the complexities of de-implementing inappropriate health interventions. Implementation Science. 2020;15(1):1-7.

30. Colquhoun HL, Carroll K, Eva KW, Grimshaw JM, Ivers N, Michie S, et al. Advancing the literature on designing audit and feedback interventions: identifying theory-informed hypotheses. Implement Sci. 2017;12(1):117.

31. Jamtvedt G, Young JM, Kristoffersen DT, O'Brien MAT, Oxman AD. Audit and feedback: effects on professional practice and health care outcomes. Cochrane database of systematic reviews. 2003(3).

32. Whittington MD, Ho PM, Helfrich CD. Recommendations for the Use of Audit and Feedback to De-Implement Low-Value Care. American Journal of Medical Quality. 2019:1062860618824153.

33. Bartholomew LK, Parcel GS, Kok G. Intervention mapping: a process for developing theory and evidence-based health education programs. Health education behavior. 1998;25(5):545-63.

34. Baumann A, Cabassa LJ, Stirman SW. Adaptation in dissemination and implementation science. Dissemination and implementation research in health: translating science to practice. 2017;2:286-300.

35. Pinnock H, Barwick M, Carpenter CR, Eldridge S, Grandes G, Griffiths CJ, et al. Standards for reporting implementation studies (StaRI) statement. Bmj. 2017;356.

36. Proctor EK, Landsverk J, Aarons G, Chambers D, Glisson C, Mittman B. Implementation research in mental health services: an emerging science with conceptual, methodological, and training challenges. Administration Policy in Mental Health Mental Health Services Research. 2009;36(1):24-34.

37. Proctor E, Silmere H, Raghavan R, Hovmand P, Aarons G, Bunger A, et al. Outcomes for implementation research: conceptual distinctions, measurement challenges, and research agenda. Adm Policy Ment Health. 2011;38(2):65-76.

38. Sanson-Fisher RW. Diffusion of innovation theory for clinical change. Medical journal of Australia. 2004;180:55-S6.

39. Niven DJ, Mrklas KJ, Holodinsky JK, Straus SE, Hemmelgarn BR, Jeffs LP, et al. Towards understanding the deadoption of low-value clinical practices: a scoping review. BMC Med. 2015;13(1):255.

40. Donaldson NE, Rutledge DN, Ashley J. Outcomes of adoption: measuring evidence uptake by individuals and organizations. Worldviews on Evidence-Based Nursing. 2004;1:41-52.

41. Weiner BJ, Lewis CC, Stanick C, Powell BJ, Dorsey CN, Clary AS, et al. Psychometric assessment of three newly developed implementation outcome measures. Implementation Science. 2017;12(1):108.

42. Pines JM, Isserman JA, Szyld D, Dean AJ, McCusker CM, Hollander JE. The effect of physician risk tolerance and the presence of an observation unit on decision making for ED patients with chest pain. Am J Emerg Med. 2010;28(7):771-9.

43. Katz DA, Williams GC, Brown RL, Aufderheide TP, Bogner M, Rahko PS, et al. Emergency physicians' fear of malpractice in evaluating patients with possible acute cardiac ischemia. Ann Emerg Med. 2005;46(6):525-33.

44. Gray P, Sullivan G, Ostryzniuk P, McEwen TA, Rigby M, Roberts DE. Value of postprocedural chest radiographs in the adult intensive care unit. Crit Care Med. 1992;20(11):1513-8.

45. Lewis CC, Fischer S, Weiner BJ, Stanick C, Kim M, Martinez RG. Outcomes for implementation science: an enhanced systematic review of instruments using evidence-based rating criteria. Implementation Science. 2015;10(1):155.

46. Wang V, Maciejewski ML, Helfrich CD, Weiner BJ, editors. Working smarter not harder: Coupling implementation to deimplementation. Healthcare: Elsevier; 2018.

47. Davidoff F. On the undiffusion of established practices. JAMA internal medicine. 2015;175(5):809-11.

48. Ubel PA, Asch DA. Creating value in health by understanding and overcoming resistance to de-innovation. Health Aff. 2015;34(2):239-44. 
49. Pontet J, Yic C, Díaz-Gómez JL, Rodriguez P, Sviridenko I, Méndez D, et al. Impact of an ultrasound-driven diagnostic protocol at early intensive-care stay: a randomized-controlled trial. The ultrasound journal. 2019;11(1):24.

\section{Figures}
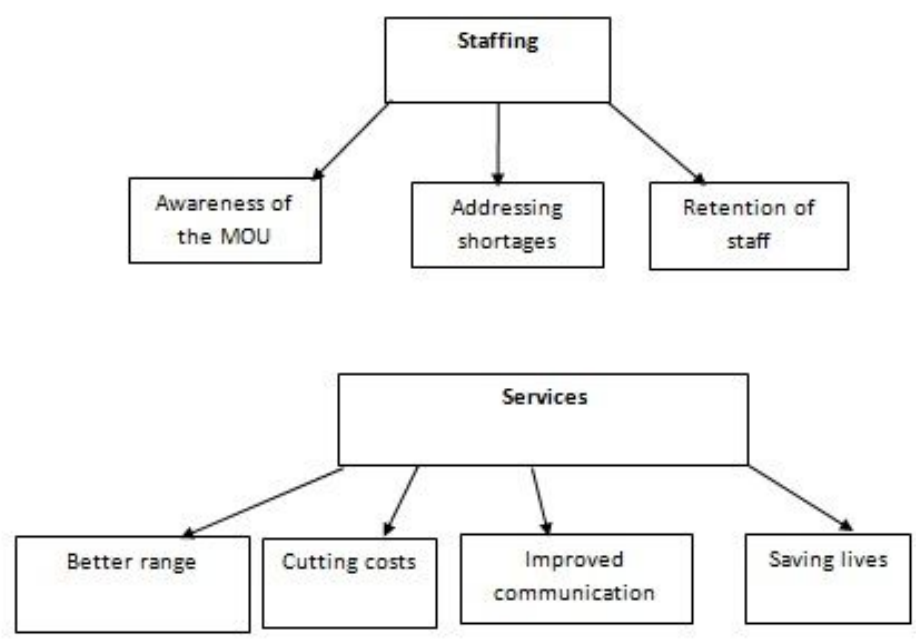

\section{Figure 1}

POCUS-guided CVC PCEP protocol consists of 3 ultrasound imaging steps. 1) Look at heart and flush catheter, 2) Look at left neck and flush catheter, 3) Look at Right lung for pleural slide

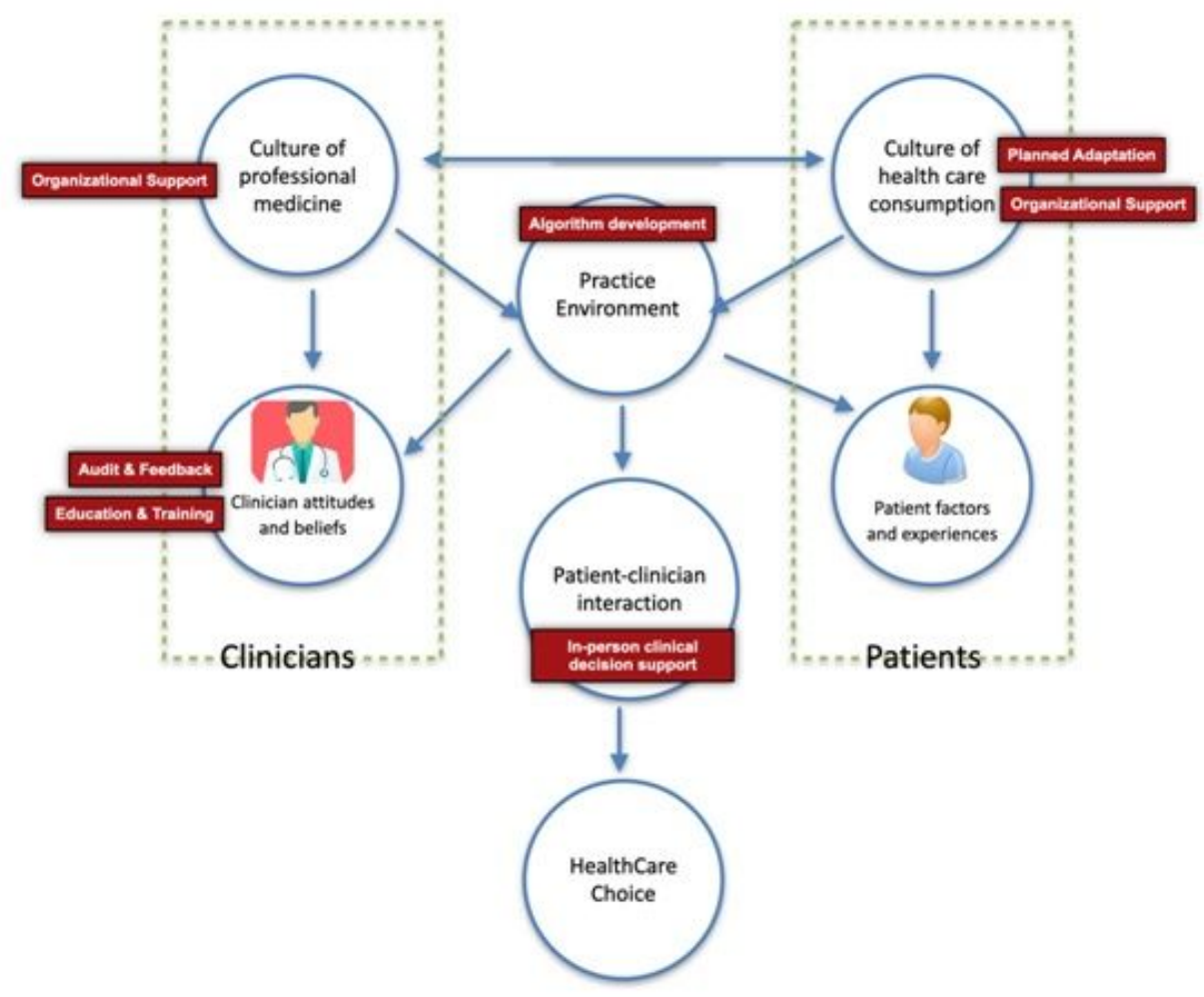

\section{Figure 2}

Morgan's Framework for understanding and reducing overuse with identified strategy bundle (red) 


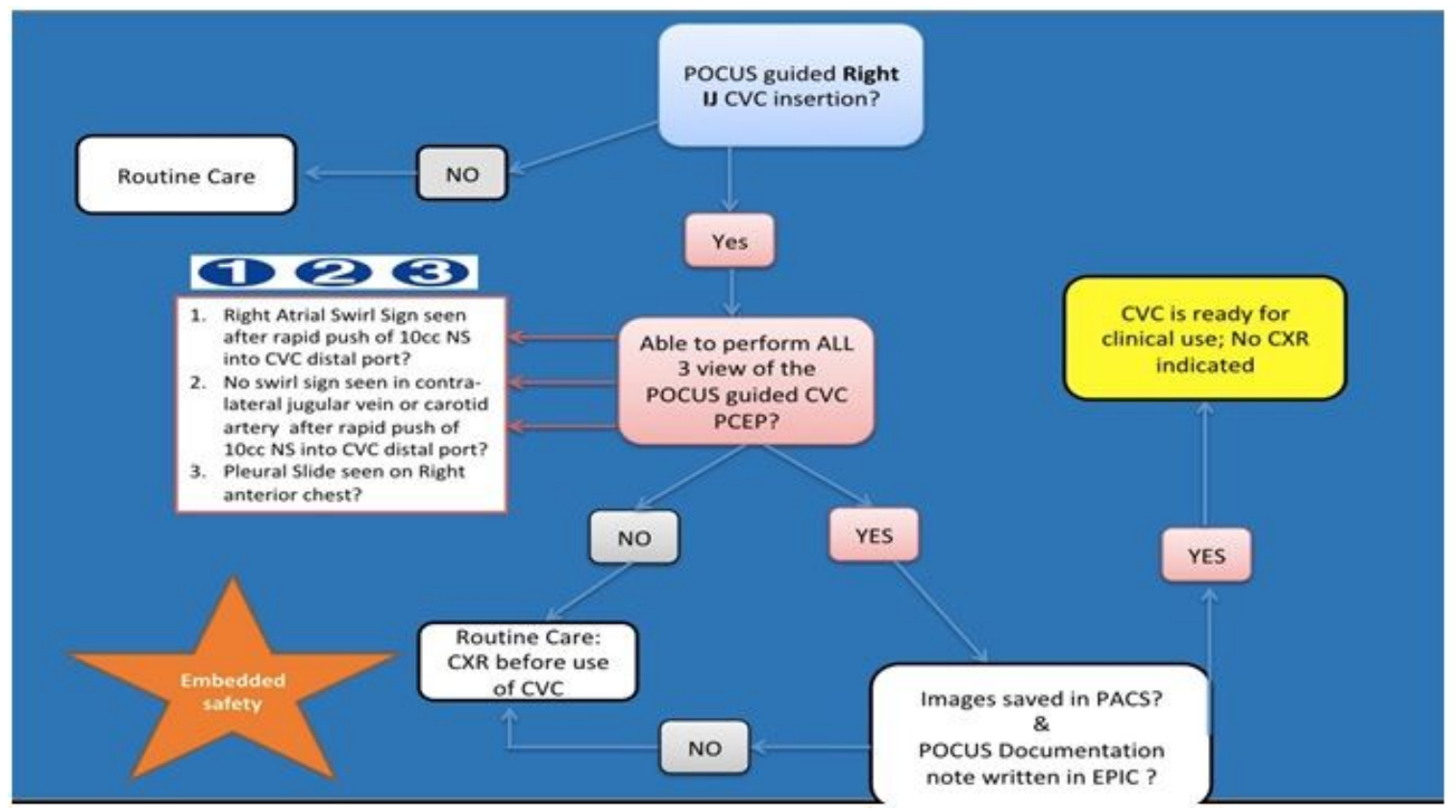

\section{Figure 3}

DRAUP algorithm for deimplementation of chest radiography after central line insertion

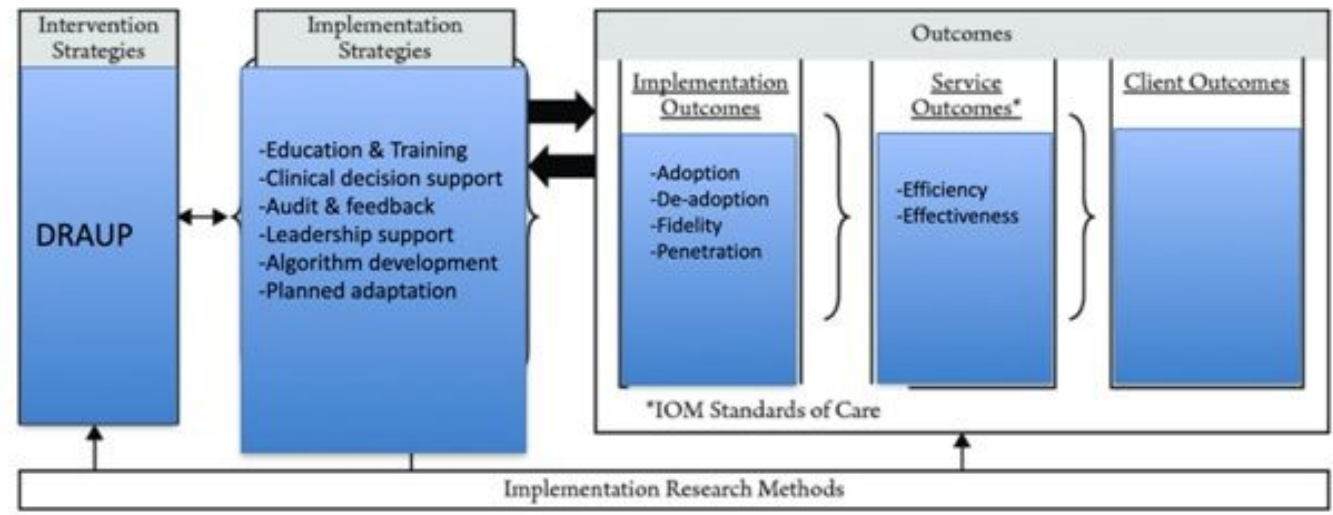

\section{Figure 4}

Operationalization using Proctor's conceptual model for implementation research (Source: Proctor et al. (2009) with embedded DRAUP strategies and outcomes.

\section{Supplementary Files}

This is a list of supplementary files associated with this preprint. Click to download.

- Supplementalfile1.FocusGroupInterviewGuide.docx

- supplementalfile2.STARIChecklist.docx 